\title{
Laws of Geography 8
}

Michael Leitner, Department of Geography and Anthropology, Louisiana State University, Philip Glasner, Department of Geoinformatics, University of Salzburg, and Ourania Kounadi, Department of Geoinformatics, University of Salzburg

https://doi.org/10.1093/acrefore/9780190264079.013.325

Published online: 26 February 2018

\section{Summary}

The most prominent law in geography is Tobler's first law (TFL) of geography, which states that "everything is related to everything else, but near things are more related than distant things." No other law in geography has received more attention than TFL. It is important because many spatial statistical methods have been developed since its publication and, especially since the advent of geographic information system (GIS) and geospatial technology, have been conceptually based on it. These methods include global and local indicators of spatial autocorrelation (SA), spatial and spatial-temporal hotspots and cold spots, and spatial interpolation. All of these are highly relevant to spatial crime analysis, modeling, and mapping and will be discussed in the main part of this text.

Keywords: Tobler's first law (TFL) of geography, spatial autocorrelation (SA), Moran's I, Geary's C, local indicator of spatial association (LISA), hotspot, kernel density estimation (KDE), geospatial privacy, geographical masking

Subjects: Criminological Theory, Geography of Crime

You do not currently have access to this article

\section{Login}

Please login to access the full content.

\section{Subscribe}

Access to the full content requires a subscription 